\title{
Severe Kala-azar and seric level of IL-6: case reports
}

\section{Calazar grave e níveis séricos de IL-6: relato de casos}

Gilmara da Rocha Brito ${ }^{1}$ (D) , Aécio da Silva Marreiros ${ }^{1}$ (D) , Izael Francisco de Brito Araujo $^{2}$ (1) Raimundo Gerônimo da Silva Júnior $^{3}$ (D) , Ingridi de Souza Sene ${ }^{4}$ (i) , Débora Cavalcante Braz ${ }^{5}$ (D)

1. Pharmacist. Faculty of Pharmacy. Federal University of Piauí. Teresina, PI, Brazil. 2. Medical Doctor. State University of Piauí. Teresina, PI, Brasil. 3. Medical Doctor. Master in Science and Health. Federal University of Piauí. Teresina, PI, Brazil. 4. Post-doctoral student's research. Leishmaniasis Research Laboratory. Federal University of Piauí. Teresina, PI, Brazil. 5. Adjunct Professor. Faculty of Pharmacy. Federal University of Piauí. Teresina, PI, Brazil.

\begin{abstract}
Introduction: IL-6 is a cytokine that participates in the systemic inflammatory process in Kala-azar, its plasma levels are high during active disease and especially in patients with severe clinical condition. Case reports: Three patients from different age groups, clinical score of severe disease and different plasma levels of IL-6 were reported. Conclusion: The results suggest that only the clinical severity score does not present sensitivity to classify, among critically ill patients, those with imminent risk of death. The IL-6 concentration seems to allow this differentiation, considering that the only fatal case, HBV/ Leishmania coinfection, presented an expressively higher plasma level.
\end{abstract}

Keywords: Kala-azar. Interleukin-6. Coinfection. Hepatitis B.

\section{Resumo}

Introdução: IL-6 é uma citocina que participa do processo inflamatório sistêmico no calazar. Seus níveis plasmáticos estão elevados durante doença ativa e, principalmente, em pacientes com quadro clínico grave. Relato de casos: foram reportados três pacientes em diferentes faixas etárias, escore clínico de doença grave e diferentes níveis plasmáticos de IL-6. Conclusão: os resultados sugerem que apenas o escore clínico não apresenta sensibilidade para classificar, entre os doentes graves, aquele com risco iminente de óbito. A concentração de IL-6 parece permitir essa diferenciação, considerando que o único caso fatal, coinfecção HBV/Leishmania, mostrou nível plasmático expressivamente mais elevado.

Palavras-chave: Calazar. Interleucina-6. Coinfecção. Hepatite B.

\section{INTRODUCTION}

Kala-azar is a severe systemic inflammatory protozoosis ${ }^{1}$. Brazil is responsible for $96 \%$ of all cases in America and the species Leishmania (L.) infantum is transmitted to humans by vector transmission ${ }^{2}$. Affected patients have a broad spectrum of clinical and laboratory manifestations and elevated levels of inflammatory cytokines such as IL-6, CXCL-8 and INF- $\gamma^{3,4}$.

The disease is lethal when not treated. Most patients have fever, anemia and hepatosplenomegaly. The therapy is usually successful. However, patients with a more severe disease have hemorrhagic manifestations, bacterial infections, edema, dyspnea, hepatitis, diarrhea, vomiting and renal failure ${ }^{5}$.

The Ministry of Health $(\mathrm{MH})$ recommends calculating the clinical or laboratory and clinical severity score of the patient with kala-azar at the time of diagnosis from indicators such as leukopenia $(<1500 \mathrm{cel} / \mathrm{dL})$, thrombocytopenia $(<50,000 \mathrm{cel} /$ $\mathrm{dL}$ ), jaundice, edema, dyspnea, bleeding, secondary infections and age groups $(<1 \text { years or }>50)^{3}$. Then, the cases with clinical scores above 4 should proceed with hospitalization ${ }^{6}$. Healthcare professionals should recognize signs and symptoms, promote early diagnosis and prognosis define appropriate therapy ${ }^{6}$, but the presence of bacterial, viral or parasitological prior infection may increase severity if not identified in a timely manner.

In the search for more sensitive indicators, determination of levels of interleukin-6 (IL-6) is not currently used in clinical routine, but is a multifunctional cytokine that plays a key role not only in the immune system but also in a variety of biological processes. In kala-azar, detection of IL-6 correlates with severe factors and death ${ }^{3,4}$.

The aim of this study is to report cases of Kala-azar patients with clinical severity scores (above 4) and report the IL-6 plasmatic levels.

\section{CASE REPORT}

The research followed the recommendations of Ethics and Research Committee of the Federal University of Piauí with 
report number 2.505.037. Plasma IL-6 concentration had been determined using the FACSCanto II flow cytometer CBA ${ }^{\circledR}$ (BD bionscience) $\mathrm{kit}^{\circledR}$. The patients were admitted to the hospital in April 2018.

\section{Report 1}

Infant, seven months, had episodes of emesis for more than a month, daily fever $\left(38-39^{\circ} \mathrm{C}\right)$, decreased appetite and weight loss. Physical examination showed increased abdominal size, mild jaundice, eupneic and hypocolored. It evolved with maintenance of febrile and emetic episodes, respiratory distress, bruising at the puncture sites and anasarche. Manifested nocturnal dry cough, small petechia on lower lip and palate, left flank hematoma and bowel movements were green even without diarrhea. As the general condition worsened and the breathing pattern was severely uncontrolled with severe dyspnea and metabolic acidosis in the course of hospitalization, the patient was transferred to the intensive care unit of a pediatric referral hospital.

He had evident pancytopenia, elevated transaminases, undetermined prothrombin time (TAP) and elevated total proteins with increased globulins and decreased albumin (Table), as well as hepatosplenomegaly evidenced by upper abdomen ultrasound. The IL-6 plasmatic concentration was $1,355.95 \mathrm{pg} / \mathrm{mL}$ and the clinical severity score was 7 .

The patient was diagnosed with kala-azar by direct bone marrow aspirate screening, and was then treated with liposomal amphotericin B. After proven clinical and laboratory improvement, he was discharged.

\section{Report 2}

A 15-year-old man presented hepatomegaly $(5 \mathrm{~cm})$, splenomegaly with palpable spleen at the level of the umbilical scar, lower limb edema, and otalgia with left bleeding. Severe anemia and leukopenia, normal platelet levels, but with increased blood clotting time (Table), IL-6 plasmatic concentration was $91.00 \mathrm{pg} / \mathrm{ml}$ and the clinical severity score was 6 . The patient presented important asthenia, decreased appetite, weight loss of $10 \mathrm{~kg}$ in three months, irregular fever, and jaundice, pallor, bleeding episodes, melena and hematuria.

On the fourth day of hospitalization, it was identified the presence of Leishmania in the bone marrow aspirate and meglumine antimoniate was administered. It progressed with improvement, the lower limb edema showed regression after the 5th day of hospitalization and hepatosplenomegaly after the 10th day. Thus, was discharged on the 28th day.

\section{Report 3}

A 34-year-old man complained of increased abdominal size, weight loss of $15 \mathrm{~kg}$ and high fever associated with chills and night sweats 2 months ago. The patient was a chronic alcoholic for 15 years but remained sober for a year when he began to show swelling of the lower limbs and abdominal pain. Patient presented episodes of epistaxis and hemoptysis. After admission to the hospital, he manifested frequent fever peaks and episodes of epistaxis were evolving, in frequency and intensity. The patient brought with him tests that revealed chronic hepatitis $\mathrm{B}$ (reagent $\mathrm{HBsAg}$ and nonreactive anti-HBs, nonreactive anti-HBc IgM, total reagent anti-HBc), portal hypertension hepatosplenomegaly and hematuria. Laboratory tests (Table) performed showed evident pancytopenia. The plasma IL-6 concentration was $8,658.61 \mathrm{pg} / \mathrm{mL}$ and the clinical severity score was 6 . At 10 days of hospitalization, the general condition was compromised, jaundiced, hypocolored skin and mucosa, dyspnea, severe abdominal pain and gastric fullness, nausea and limb edema still persisted. After medical assessment, he was transferred to the intensive care unit.

Leishmania amastigotes in bone marrow aspirate confirmed Kala-azar and treatment was initiated with liposomal amphotericin B. After four days of admission to the intensive care unit, he presented loose, blackish and foul-smelling stools and oscillations in oximetry. With the increasing unstable clinical condition, he died after three cardiorespiratory arrests.

Table Laboratory parameters of case reports. Piauí, Brazil, 2018.

\begin{tabular}{|c|c|c|c|}
\hline Laboratory tests (unit) & Report 1* & Report 2* & Report 3+ \\
\hline $\begin{array}{l}\text { Erythrocytes (millions/ } \\
\mathrm{mL} \text { ) }\end{array}$ & 2.1 & 3.93 & 3.19 \\
\hline Hemoglobin (g/dL) & 6.3 & 7.09 & 8.25 \\
\hline Hematocrit (\%) & 19 & 23.5 & 24.7 \\
\hline Leukocytes (cells/mL) & 4,200 & 1,600 & 3,220 \\
\hline Platelets counts $(/ \mu \mathrm{L})$ & 39,000 & 257,000 & 94,700 \\
\hline Urea (mg/dL) & 20 & 16 & 130 \\
\hline Creatinine (mg/dL) & 0.5 & 0.8 & 2.2 \\
\hline $\begin{array}{l}\text { Aspartate/Alanine } \\
\text { aminotransferases }(\mathrm{U} / \mathrm{mL})\end{array}$ & $68 / 36$ & $131 / 52$ & $31 / 20$ \\
\hline prothrombin (INR) & 1.40 & $€$ & 1.49 \\
\hline Total protein $(\mathrm{g} / \mathrm{dL})$ & 8.4 & 7.0 & $€$ \\
\hline Albumin (g/dL) & 3.4 & 2.1 & $€$ \\
\hline Globulin (g/dL) & 5.0 & 4.9 & $€$ \\
\hline IL-6 levels (pg/mL) & $1,355.95$ & 91.00 & $8,658.61$ \\
\hline
\end{tabular}

Legend: * Initial laboratory tests in hospital. ${ }^{+}$Admission to the intensive care unit. ${ }^{€}$ No available laboratory tests.

\section{DISCUSSION}

According to the Health Surveillance Guide ${ }^{6}$, patients in this study had a clinical severity score greater than 4 at admission and therefore received hospital treatment. Adult co-infected with Leishmania/HBV and infant had higher severity and higher IL-6 concentrations. However, the score did not allow 
identifying which of the patients in this study had an imminent risk of death because the child, the adult and the adolescent had scores 7, 6 and 6, respectively. Thus, only the clinical score did not identify the fatal case of this study, probably because it did not include previous viral infections such as HBV. However, the high IL-6 concentration in the Leishmania/HBV coinfected patient was a differential; $8,658.61 \mathrm{pg} / \mathrm{mL}$ was well above the values reported in the scientific literature for fatal outcomes, which started at $200 \mathrm{pg} / \mathrm{mL}^{4}$. This patient had classic clinical manifestations of kala-azar but was only diagnosed with coinfection at the hospital. In this case, the IL-6 concentration showed higher sensitivity and could be used to alert the health team about the clinical severity of the patient.

Children under the age of 2 years with kala-azar are considered a risk group for severe disease because when infected they develop a more intense inflammatory process represented by higher levels of IL-6 and INF- $\gamma^{3}$. Case reports showed that IL-6 concentration was higher in children compared to adolescents. The presence of IL- 6 contributes to many clinical and laboratory manifestations and correlates with death ${ }^{3}$. All three cases had severe anemia and IL-6 appears to contribute to anemia by increasing hepcidin levels and decreasing serum iron ${ }^{7}$. Hepcidin promotes intracellular iron accumulation and decreases the iron available for bone marrow erythrocyte maturation, thus contributing to anemia. In human kala-azar, IL-6 showed a significant negative correlation with hemoglobin ${ }^{3}$, but there is no scientific evidence of increased levels of hepcidin in the disease.

The presence of bleeding in Kala-azar is an important indicator of severity. The more number of bleeding sites of sites (epistaxis, petechiae, hematoma, haematuria, haemoptysis, gastrointestinal bleeding, persistence of puncture site bleeding) the greater clinical severity ${ }^{3,4}$. IL- 6 also contributes to these bleeding events and appears to interfere with levels of fibrin and D-dimer degradation products ${ }^{3}$. In this case report, the first and third cases showed more bleeding sites and higher plasma levels of IL-6. Epistaxis can be seen in Kala-azar, but in the coinfected patient it was frequent and intense. IL-6 contributes to fibrinogenesis, the formation of varicose veins, increases the risk of bleeding and death in cases of liver cirrhosis ${ }^{9}$.
Liver and spleen lesions caused by the Leishmania parasite induce hepatosplenomegaly. As the liver is the major source of clotting factors and plasma proteins, liver lesions increase serum levels of transaminases and prothrombin action time. In addition, they reduce albumin levels and increase in globulins, contributing to the formation of lower limb edema, a clinical manifestation reported in all three cases. The transaminases level of the coinfected Leishmania/HBV patient was below 100 IU indicating probably a reduced liver function ${ }^{10}$.

The spleen presents intense inflammatory activity and high parasitic load in Kala-azar. In this study, hypersplenism was reported in all three patients and is responsible for splenic sequestration of the blood elements, contributing to pancytopenia ${ }^{11}$. In patients with successive disease recurrences, splenectomy increases remission time ${ }^{12}$.

The presence of bacterial infection is an important parameter of severity ${ }^{3,4}$, the adolescent presented suppurative otitis, while the infant developed pneumonia during hospitalization. In this case report, Leishmania and HBV coinfection had a fatal outcome. Leishmania induces an immunosuppressive response by decreasing TNF- $\alpha$ and increasing $\mathrm{IL}-10$ production ${ }^{13}$ by macrophages, promoting an environment for HBV replication. As observed in this study, there is a report of fulminant acute hepatitis B (HBsAg and anti-HBc-IgM reagents) infection after Leishmania infection resulting in death ${ }^{14}$. A previous case report described a case of Leishmania coinfection and hepatitis $C$ virus that continued with the cure of protozoosis ${ }^{15}$.

Regarding the specific treatment for Kala-azar, the use of liposomal amphotericin B was properly prescribed to patients 1 and 3 because they were, respectively, under 1 year old and with comorbidity that compromised immunity, both having a clinical severity score greater than $4^{6}$. Thus, the reports, according to literature ${ }^{1,3,4,5}$, suggest that the determination of IL-6 plasmatic concentration in patients with Kala-azar, is more relevant than the clinical severity score to identify patients at imminent risk of death, however a broader study that evaluates a greater number of patients is necessary to further validate this hypothesis.

\section{REFERENCES}

1. Costa CHN, Werneck GL, Costa DL, Holanda TA, Aguiar GB, Carvalho AS, et al. Is severe visceral leishmaniasis a systemic inflammatory response syndrome ? A case control study. Rev Soc Bras Med Trop. 2010;43(4):386-392.

2. Organização Pan-Americana Saúde. Leishmanioses: informe epidemiológico das Américas. Washington: Organização Pan-Americana da Saúde; 2018; (6):17.

3. Costa DL, Rocha RL, Carvalho RMA, Lima-Neto AS, Harhay MO, Costa $\mathrm{CHN}$, et al. Serum cytokines associated with severity and complications of kala-azar. Pathog Glob Health. 2013;107(2):78-87. doi:10.1179/204777321 3y.0000000078.

4. dos Santos PL, de Oliveira FA, Santos MLB, Cunha LCS, Lino MTB, Oliveira MFS, et al. The Severity of Visceral Leishmaniasis Correlates with Elevated Levels of
Serum IL-6, IL-27 and sCD14. PLoS Negl Trop Dis. 2016;10(1). doi:10.1371/ journal.pntd.0004375.

5. De Queiroz Sampaio MJA, Cavalcanti NV, Alves JGB, Fernandes Filho MJC, Correia JB. Risk factors for death in children with visceral leishmaniasis. PLoS Negl Trop Dis. 2010; 4(11):e877. doi:10.1371/journal.pntd.0000877.

6. Brasil. Ministério da Saúde. Secretaria de Vigilância em Saúde. CoordenaçãoGeral de Desenvolvimento da Epidemiologia em Serviços. Guia de Vigilância em Saúde. 1. ed. atual. Brasília: Ministério da Saúde, 2016.

7. Nemeth E, Rivera S, Gabayan V, Keller C, Taudorf S, Pedersen BK, et al. IL-6 mediates hypoferremia of inflammation by inducing the synthesis of the iron regulatory hormone hepcidin. J Clin Invest. 2004;113 (9): 1271-1276. doi:10.1172/JCl200420945. 
8. Sigdel B, Bhandary S, Rijal S. Epistaxis in visceral leishmaniasis with hematological correlation. Int J Otolaryngol. 2012; 2012: 10-12. doi:10.1155/2012/809056.

9. Kao J-T, Yu C-J, Feng C-L, Tsai S-M, Chen Y-L, Wu Y-Y. IL-6 significantly correlates with p-STAT3 expression and presents high variceal bleeding with mortality in cirrhotic patients: A cross-sectional study. J Microbiol Immunol Infect. 2017; 50: 286-296. doi:10.1016/j.jmii.2015.03.001.

10. Adam AOA, Dafalla MMM, Mohammed HAA, Elamin MY, Younis M, Elfaki $\mathrm{MEE}$, et al. Visceral leishmaniasis-hepatites $\mathrm{B} / \mathrm{C}$ coinfections: a rising a necessity to triage patients for treatment. Ann Saudi Med. 2014; 34(2): 143-146. doi:10.5144/0256-4947.2014.143.

11. Varma N, Naseem S. Hematologic changes in visceral Leishmaniasis/Kala Azar. Indian J Hematol Blood Transfus. 2010; 26(3): 78-82. doi:10.1007/s12288010-0027-1.
12. Alon D, Chowers M. Successful therapeutic splenectomy in an HIV patient with relapsing visceral leishmaniasis. Int J STD AIDS. 2012; 23(4): 289-290. doi:10.1258/ijsa.2009.009234.

13. Roy S, Mukhopadhyay D, Mukherjee S, Ghosh S, Kumar S, Sarkar K, et al. A Defective Oxidative Burst and Impaired Antigen Presentation are Hallmarks of Human Visceral Leishmaniasis. J Clin Immunol. 2015; 35(1): 56-67. doi:10.1007/ s10875-014-0115-3.

14. Godoy P, Salles G De O. Associação de leishmaniose visceral e hepatite B de curso fulminante: relato de um caso. Rev Soc Bras Med Trop. 2002; 35(5): 515-518.

15. Colomba C, Saporito L, Di Carlo P, Tolomeo M, Cervo A, Firenze A, et al. Direct-acting antivirals and visceral leishmaniasis: a case report. BMC Infect Dis. 2019; 19(1): 328. doi:10.1186/s12879-019-3947-x 